\title{
Акустический анализ дыхательных звуков в диагностике заболеваний легких
}

ГОУ ВПО "Дагестанская государственная медицинская академия": 367012, Махачкала, пл. Ленина, 1

\section{A.A.Guseinov}

\section{Acoustic analysis of breathing sounds in diagnosis of pulmonary diseases}

\begin{abstract}
Summary
Bronchophonography (BPG) is a novel method of objective assessment of breathing sounds. This method was applied in 166 patients with obstructive lung pathology (bronchial asthma and COPD), 17 patients with restrictive diseases, and 108 healthy persons. Additionally, spirometry and total body plethysmography were used in those patients. Acoustic equivalent of work of respiratory muscles (AWM) was determined within different frequency ranges from 200 to $12,600 \mathrm{~Hz}$ under tidal and forced breathing. Near 2500 breathing patterns (amplitude and frequency of breathing sounds) were analyzed. AWM significantly differed between groups of patients and various frequency ranges, namely between healthy and obstructive patients in medium frequency range $(1.2-5.0 \mathrm{kHz})$, between obstructive and restrictive patients in high frequency range $(5.0-12.6 \mathrm{kHz})$, between healthy and restrictive patients through all the spectrum $(1.2-12.6 \mathrm{kHz})$ and particularly in high frequency range. Therefore, BPG could be used as an additional objective measure in diagnosis of lung diseases.

Key words: lung diseases, bronchophonography, acoustic analysis, respiratory sounds.
\end{abstract}

\section{Резюме}

Одним из новых методов объективной оценки дыхательных звуков является бронхофонография (БФГ). Проведено исследование больных с обструктивными заболеваниями (О3) - бронхиальной астмой и хронической обструктивной болезнью легких, рестриктивными заболеваниями легких (Р3) и здоровых лиц (ЗЛ). В качестве дополнительных методов исследования использовались спирометрия и общая бодиплетизмография. Обследованы 166 пациентов с О3, 17 - с Р3 и 108 зЛ. Определяли акустический эквивалент работы дыхательных мышц (АРД) в различных частотных диапазонах от 200 до 12600 Гц при спокойном и форсированном дыхании. Проведен анализ около 2500 дыхательных паттернов (амплитудно-частотных характеристик спектра дыхательных шумов). Получены значимые различия между показателями АРД исследуемых групп в различных диапазонах: преимущественно в среднечастотном $(1,2-5,0$ кГц $)-$ между 3Л и больными О3, в высокочастотном $(5,0-12,6$ кГц) - между больными О3 и Р3, по всему спектру $(1,2-12,6$ кГц) и особенно в его высокочастотной части - между ЗЛ и больными РЗ. Таким образом, БФГ может использоваться для получения дополнительных объективных оценочных параметров при диагностике заболеваний легких.

Ключевые слова: заболевания легких, бронхофонография, акустический анализ, дыхательные звуки.

Аускультация является важным методом исследования в диагностике заболеваний легких. За последние 20 лет появились и продолжают развиваться новые технологии в легочной диагностике акустическими средствами, что сделало возможным цифровой анализ дыхательных звуков в клинической практике. Интегрирование параметров дыхательных звуков со спирометрическими данными расширяет возможности диагностики у больных с легочной патологией [1]. Акустический анализ позволяет мониторировать состояние верхних и нижних дыхательных путей, оценивать региональную вентиляцию и эффективность проводимой терапии [2]. При использовании стетофонендоскопов возможности интерпретации звуков ограниченны, особенно при аускультации легких, которая требует более качественной передачи звуков [3]. Существует целый ряд технических проблем, препятствующих внедрению акустического анализа в повседневную клиническую практику. В частности, необходимы разработка прочного и недорогого датчика для записи легочных звуков, усовершенствование автоматического распознавания и отсечения артефактов, раздельная обработка основных и добавочных дыхательных звуков [4, 5].
Многие проблемы компьютерного анализа легочных звуков еще далеки от разрешения. Большинство работ посвящено исследованию дыхательных шумов в диапазоне $\leq 1-2$ кГц [6, 7], при котором производится запись с различных участков грудной клетки. Естественно, что различия в анатомофизиологических параметрах обследуемых лиц затрудняют стандартизацию получаемых данных, т. к. при прохождении звуков через стенку грудной клетки теряется большая часть высокочастотных компонентов [8].

Новым этапом в развитии современных методов акустического анализа дыхательных звуков стала разработка компьютерно-диагностического комплекса (КДК) "Паттерн" на кафедре инженерной экологии и охраны труда МЭИ (ТУ) (Россия) [9, 10]. Принципиально новым решением является то, что с помощью КДК регистрация (сканирование) респираторного цикла производится через высокочувствительный датчик, помещаемый в ротовую полость пациента. Принцип его работы основан на фиксировании и последующей оценке амплитудно-частотных характеристик спектра дыхательных звуков, составивших основу метода бронхофонографии (БФГ). 
С помощью прикладной программы Pattern Analyzer данные обрабатываются для расчета количественных показателей, характеризующих респираторный цикл АРД - это выраженный в мДж акустический эквивалент работы дыхательных мышц в различных частотных диапазонах (АРД $0-0,2-1,2$ кГц, "нулевой", или низкочастотный диапазон; АРД 1 1,2-12,6 кГц, общий; АРД $2-5,0-12,6$ кГц, высокочастотный; АРД $-1,2-5,0$ кГц, среднечастотный диапазон). К - коэффициент, отражающий те же параметры в относительных единицах $\left(\mathrm{K}_{1}=\mathrm{APД}_{1} /\right.$ АРД $Д_{0} \times 100$, отражает весь спектр частот; $\mathrm{K}_{2}=$ АРД $_{2} /$ АРД $Д_{0} \times 100$, высокочастотный диапазон; $\mathrm{K}_{3}=$ АРД $_{3} /$ АРД ${ }_{0} \times 100$, среднечастотный диапазон). КДК рекомендован к запуску в производство и применению в медицинской практике комитетом по новой медицинской технике МЗ РФ (протокол № 4 заседания комиссии по аппаратам, приборам и инструментам от 28.04.2000).

Цель настоящего исследования - изучение цифровых акустических параметров (паттернов) дыхания у пациентов с заболеваниями легких.

\section{Материалы и методы}

В исследовании участвовали 108 практически здоровых лиц (средний возраст - 35,16 \pm 1,37 года), 166 больных обструктивными заболеваниями - О3 (91 пациент с бронхиальной астмой (БА), 62 - с хронической обструктивной болезнью легких (ХОБЛ) и13 с симптомами обоих заболеваний; средний возраст $52,07 \pm 1,21$ года) и 17 больных рестриктивными заболеваниями - Р3 (легочный фиброз, экзогенный аллергический альвеолит, саркоидоз, постлучевой фиброз; средний возраст - 56,35 \pm 2,2 года).

Критериями включения в исследование были письменное согласие на участие в исследовании, возраст пациентов $\geq 18$ лет. Группу здоровых лиц (ЗЛ) составили добровольцы с отсутствием жалоб на момент исследования и нормальными показателями функции внешнего дыхания (ФВД). В группы больных с О3 вошли пациенты с диагнозами ХОБЛ и БА, соответствующими критериям GOLD (2006) и GINA (2005).

БФГ-исследование проводили при спокойном и форсированном дыхании. Записывали не менее 3 дыхательных циклов при каждом режиме. При выполнении БФГ-теста обязательным было выполнение следующих условий:

- отсутствие посторонних звуков в помещении в течение записи;

- длительность записи - не менее 4 с;

- выдох при форсированном дыхании производился резко, с максимальным усилием с начала и до конца, без раздувания щек.

Спирометрические и бодиплетизмографические исследования выполнялись на оборудовании Master Screen-Body (Erich Jaeger, Германия) и "Этон-01" (Россия), не ранее чем через 1-1,5 ч после приема пищи. Исключали курение, физические и нервные нагрузки.
После проведения исследования анализировались следующие параметры:

- АРД $_{0}$, АРД 1, АРД 2, АРД $, \mathrm{K}_{1}, \mathrm{~K}_{2}, \mathrm{~K}_{3}$;

- прирост показателей коэффициентов $\mathrm{K}(\Delta \mathrm{K})$, который определялся как $\mathrm{K}_{\text {форс. }}-\mathrm{K}_{\text {спок. }} / \mathrm{K}_{\text {спок. }}$ $\times 100$, где $\mathrm{K}_{\text {форс. }}-$ показатель при форсированном, а К спок. - при спокойном дыхании;

- индекс прироста К (ИПК), т. е. отношение $\Delta \mathrm{K}_{2}$ / $\Delta \mathrm{K}_{1}$.

При статистической обработке материала применяли непараметрические критерии, т. к. распределение показателей АРД отличалось от нормального. Для характеристики вариации вычисляли медиану $(\mathrm{Me})$ и 25-й и 75-й процентили. Статистическую значимость различия между показателями АРД в различных группах оценивали по критериям Крускала-Уоллиса и Манна-Уитни с учетом поправки Бонферрони при множественных сравнениях.

\section{Результаты}

Полученные результаты сведены в табл. 1, 2 и 3. Как видно из табл. 1 и 2, были получены достоверные отличия между группой ЗЛ и больными О3 $(p<0,05)$ по показателям АРД 1, АРД $_{3}, \mathrm{~K}_{1}, \mathrm{~K}_{3}$ (т. е. по всему спектру в целом и в среднечастотном диапазоне) при спокойном дыхании. При этом АРД 1 и АРД ${ }_{3}, \mathrm{~K}_{1}$ и $\mathrm{K}_{3}$ у пациентов с О3 выше, чем у ЗЛ. При форсированном дыхании различия выявлены по всем диапазонам - АРД 0, АРД $_{1-3}$, но при этом уменьшаются в отношении $\mathrm{K}(p>0,05)$. Существенные различия отмечаются и между ЗЛ и больными Р3, но уже в других диапазонах АРД. А показатели АРД 0 , АРД 2 , $\mathrm{K}_{2}$ у ЗЛ выше, чем у пациентов с РЗ. При этом, в отличие от больных О3, при форсированном дыхании различия между группами ЗЛ и больными Р3 становятся несущественными, за исключением $\mathrm{K}_{3}$ (среднечастотный спектр). Между показателями групп больных О3 и Р3 также выявлены различия: значения АРД 0 и АРД 2 достоверно выше при О3.

Как следует из табл. 3 , по показателю $\Delta K$ отличия выявлены между ЗЛ и больными О3 в общем диапазоне $\left(\Delta \mathrm{K}_{1}\right)$, преимущественно - в высокочастотном $\left(\Delta \mathrm{K}_{2}\right)$, а также между ЗЛ и больными РЗ в среднечастотном диапазоне $\left(\Delta \mathrm{K}_{3}\right)$. Доверительный интервал Ме ИПК составил (в пределах 25-го и 75-го процентилей): в группе 3Л - 0,35-1,76, у больных О3 $1,16-4,04$ и у пациентов с Р3 - 1,26-4,18.

Таким образом, выявлены существенные различия между ЗЛ и больными О3 и Р3, но различия значений данного показателя между группами больных не обнаружены.

\section{Обсуждение}

Поиск новых функциональных методов исследования, доступных для применения в повседневной врачебной практике и вместе с тем позволяющих достаточно точно оценить и объективизировать легочную акустику, остается актуальным и в настоящее время. Трудно не согласиться, что оценка легочных 
Таблица 1

Различия показателей АРД в группах исследуемых

\begin{tabular}{|c|c|c|c|c|c|c|c|c|c|c|c|c|}
\hline \multirow[t]{2}{*}{ Показатели } & \multicolumn{3}{|c|}{$\mathrm{AP}_{0}$} & \multicolumn{3}{|c|}{$\mathrm{AP}_{1}$} & \multicolumn{3}{|c|}{$\mathrm{APA}_{2}$} & \multicolumn{3}{|c|}{$\mathrm{APA}_{3}$} \\
\hline & зл & 03 & P3 & зл & 03 & P3 & зл & 03 & P3 & зл & 03 & P3 \\
\hline \multirow[t]{2}{*}{$n$} & 108 & 166 & 17 & 108 & 166 & 17 & 108 & 166 & 17 & 108 & 166 & 17 \\
\hline & 108 & $154^{*}$ & $15^{*}$ & 108 & $154^{*}$ & $15^{*}$ & 108 & $154^{*}$ & $15^{\star}$ & 108 & $154^{*}$ & $15^{*}$ \\
\hline \multirow[t]{2}{*}{ Me } & 676,1 & 594,0 & 345,7 & 45,7 & 95,5 & 51,6 & 4,7 & 3,7 & 1,7 & 38,7 & 89,5 & 49,7 \\
\hline & 1626,5 & 1789,9 & 1382,5 & 706,4 & 874,6 & 703,3 & 53,7 & 78,5 & 41,3 & 641,7 & 793,5 & 663,4 \\
\hline \multirow[t]{2}{*}{$p_{1-2}$} & & 1,000 & & & 0,000 & & & 1,000 & & & 0,000 & \\
\hline & & 0,002 & & & 0,000 & & & 0,002 & & & 0,000 & \\
\hline \multirow[t]{2}{*}{$p_{1-3}$} & & 0,040 & & & 1,000 & & & 0,003 & & & 1,000 & \\
\hline & & 0,201 & & & 1,000 & & & 0,869 & & & 1,000 & \\
\hline \multirow[t]{2}{*}{$p_{2-3}$} & & 0,014 & & & 0,112 & & & 0,016 & & & 0,167 & \\
\hline & & 0,006 & & & 0,263 & & & 0,017 & & & 0,402 & \\
\hline
\end{tabular}

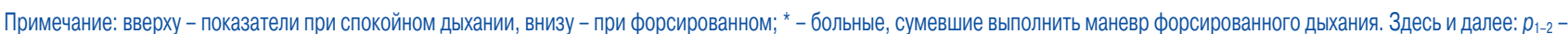
статистическая достоверность различий между группами ЗЛ и больных 03, p 1-3 - статистическая достоверность различий между группами 3Л и больных Р3, $p_{2-3}$ - статистическая достоверность различий между группами больных 03 и Р3.

шумов с помощью фонендоскопа субъективна и в значительной степени зависит от уровня подготовки врача, его опыта и способности дифференцировать различные звуковые паттерны. Нелегко определять количественные параметры звуков, документировать проводимые исследования, осуществлять длительный мониторинг. Необходимо учитывать, что фонендоскоп значительно снижает реальный частотный диапазон легочных звуков. Чтобы избежать врачебных ошибок и повысить уровень диагностики, необходимы простые, доступные методы исследования, позволяющие более глубоко и объективно оценить клинические аускультативные данные. Изучение акустических характеристик легочных звуков является перспективным и многообещающим направлением.

В литературе встречаются описания различных методов изучения дыхательных шумов. Пневмофонография - исследование дыхательных шумов с определением амплитуды и частоты спектра параллельно тяжести бронхолегочного процесса, в ходе которого выполняется компьютерный спектральный анализ параметров звуков с помощью сенсорных датчиков на трахее и грудной стенке [11]. Туссофонобарография анализ звука кашлевого толчка [12]. Трахеофонография - анализ шума над трахеей, возникающий при выполнении маневра форсированного выдоха [13]. В Европе осуществляется проект исследований по стандартизации компьютерного анализа легочных звуков (CORSA - Computerized Respiratory Sound Analysis). Большинство исследований ведется в диапазоне 1-2 кГц, что, думается, существенно сужает диапазон частот, используемых для акустического анализа. Применяемая при этом аппаратура - хрупкая и дорогостоящая. Часто отсутствует количественная оценка акустических феноменов. Результаты исследований носят описательный характер [1, 4]. В России метод БФГ был использован для выявления обструктивных нарушений ФВД и оценки их динамики в процессе лечения у детей, страдающих БА. Было выявлено, что у детей раннего возраста БФГ позволяет выявлять обструктивный синдром на до- клинической стадии заболевания [14]. По данным сотрудников Владивостокского государственного медицинского университета, проводивших сравнительный анализ данных билатеральной БФГ и рентгенографии для выявления патологического очага в легких, чувствительность метода составляет $75 \%$, а специфичность $-87 \%$ [15].

Результаты настоящего исследования показали, что звуковой спектр в исследуемых группах заметно отличается. Особенно заметны расхождения в группах ЗЛ и больных О3. Это показатели АРД, АРД $\mathrm{K}_{1}, \mathrm{~K}_{3}$ (по всему спектру частот в целом и особенно в его среднечастотной части) в режиме спокойного дыхания. Интересно, что в режиме форсированного дыхания еще больше возрастают различия АРД АРД ${ }_{1-3}, \mathrm{~K}_{1}, \mathrm{~K}_{2}, \Delta \mathrm{K}_{1}, \Delta \mathrm{K}_{2}$, ИПК (практически во всех частотных диапазонах). Это не противоречит и клинической практике: при скудных аускультативных данных врачи часто просят больного дышать глубоко и форсированно и начинают прослушивать хрипы, которых не было при спокойном дыхании. Кроме того, было выявлено, что у ЗЛ $\Delta \mathrm{K}$ во всех диапазонах практически одинакова и превышает 400 \% (по $\mathrm{Me}$ ), а у больных О3 в высокочастотном диапазоне $\left(\mathrm{K}_{2}\right)$ регистрируется значительный прирост, сопоставимый с показателями ЗЛ. Но в среднечастотном диапазоне и по всему спектру значения существенно ниже (164,9 \% и 185,9 \% соответственно), т. е. имеет место т. н. "срыв турбулентности". Это позволило ввести ИПК, который существенно отличается в исследуемых группах. Так, показатель ИПК > 2 может указывать на наличие обструктивных нарушений ФВД. Точность диагноза повышается при комплексном учете показателей АРД и К. Данные различия позволили предложить алгоритм диагностики О3: показатели АРД 1 и АРД $>100$ мДж при спокойном дыхании и > 900 мДж - при форсированном; $\mathrm{K}_{1}, \mathrm{~K}_{3}$ $>15$ при спокойном дыхании и > 50 - при форсированном; $\Delta \mathrm{K}_{1}$ и $\Delta \mathrm{K}_{3}<200 \%$; ИПК $>2$ (т. е. всего 11 показателей). Чувствительность, специфичность и диагностическая эффективность метода определялись у 129 ЗЛ (в состав основной группы ЗЛ вошел 
Таблица 2

Различия показателей К в группах исследуемых

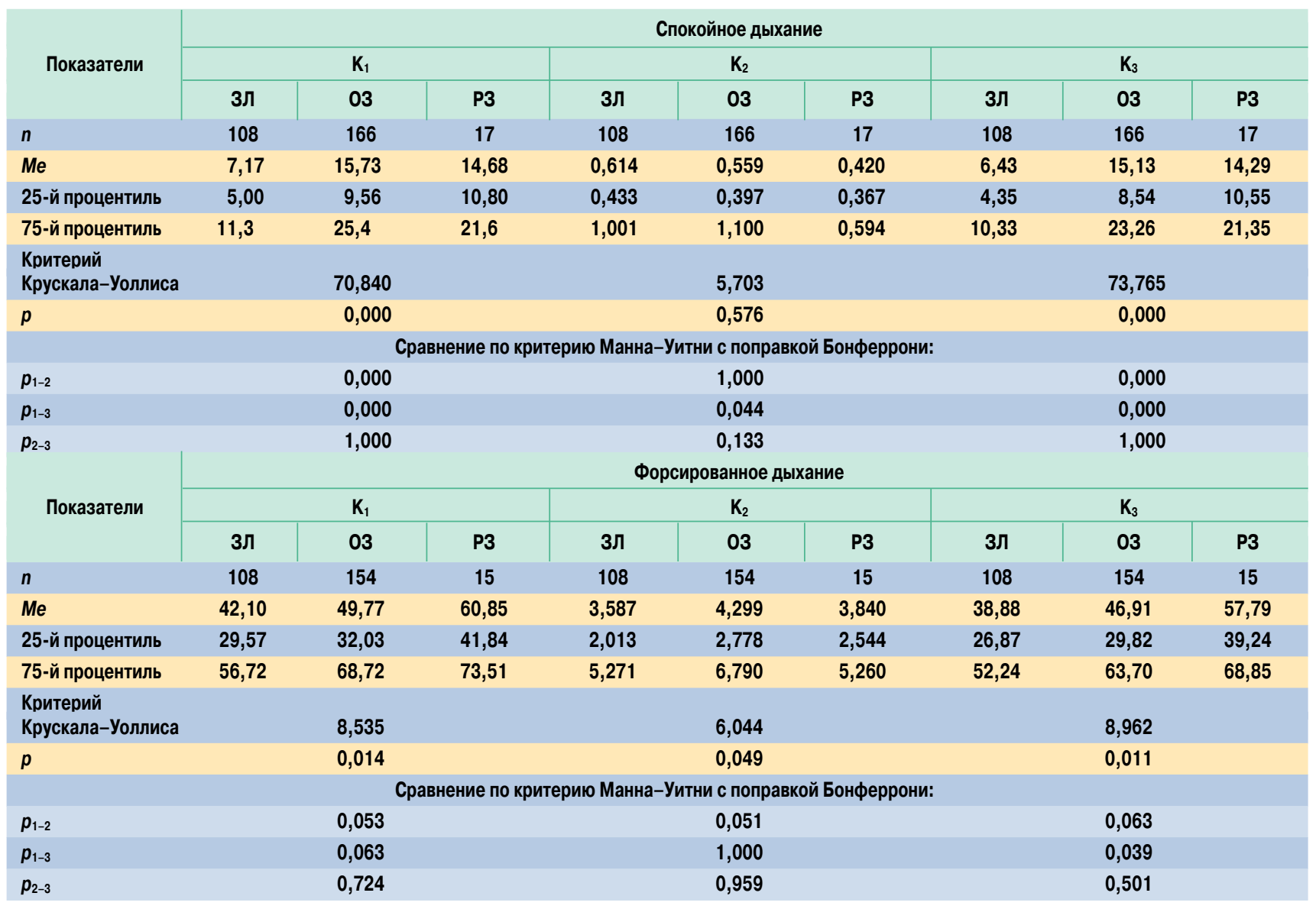

еще 21 человек в соответствии с критериями включения) и 154 больных О3 (из основной группы были исключены лица, у которых не был определен хотя бы 1 из 11 параметров). Были изучены 3 варианта диагностического алгоритма.

1. "Максимальный" вариант: учитывались все 11 параметров. Специфичность составила $100 \%$ (у всех 129 человек из группы ЗЛ были получены истинно отрицательные результаты), чувствительность 7,8 \% (из 154 больных О3 истинно положительный результат выявлен только у 12), диагности- ческая эффективность - 49,8 \%. Таким образом, если при обследовании у пациента получен истинно положительный результат, то с высокой вероятностью можно предположить наличие у него выраженных обструктивных нарушений ФВД.

2. "Минимальный" вариант: хотя бы 1 из 11 исследуемых параметров соответствовал критериям обструктивных нарушений. В этом случае специфичность составляла $34,1 \%$, чувствительность $87,7 \%$, а диагностическая эффективность 63,3 \%. Учитывая, что из 129 ЗЛ у 85 был получен

Таблица 3

Прирост показателей К при выполнении форсированного выдоха (\%)

\begin{tabular}{|c|c|c|c|c|c|c|c|c|c|}
\hline \multirow[t]{2}{*}{ Показатели } & \multicolumn{3}{|c|}{$\Delta \mathrm{K}_{1}$} & \multicolumn{3}{|c|}{$\Delta \mathrm{K}_{2}$} & \multicolumn{3}{|c|}{$\Delta \mathrm{K}_{3}$} \\
\hline & зл & 03 & P3 & зл & 03 & P3 & зл & 03 & P3 \\
\hline$n$ & 108 & 154 & 15 & 108 & 154 & 15 & 108 & 155 & 15 \\
\hline Me & 406,84 & 185,90 & 288,69 & 411,458 & 515,672 & 597,384 & 430,01 & 164,90 & 280,83 \\
\hline 25-й процентиль & 227,14 & 73,42 & 183,10 & 147,568 & 241,076 & 435,253 & 239,18 & 64,36 & 170,06 \\
\hline 75-й процентиль & 830,9 & 432,0 & 580,2 & 825,565 & 1033,830 & 1126,627 & 853,29 & 401,58 & 547,65 \\
\hline \multicolumn{2}{|l|}{$\begin{array}{l}\text { Критерий } \\
\text { Крускала-Уоллиса }\end{array}$} & \multicolumn{3}{|l|}{33,509} & \multicolumn{2}{|l|}{6,044} & \multicolumn{3}{|c|}{8,962} \\
\hline$p$ & \multicolumn{3}{|c|}{0,000} & \multicolumn{3}{|c|}{0,049} & \multicolumn{3}{|c|}{0,011} \\
\hline \multicolumn{10}{|c|}{ Сравнение по критерию Манна-Уитни с поправкой Бонферрони: } \\
\hline$p_{1-2}$ & \multicolumn{3}{|c|}{0,000} & \multicolumn{3}{|c|}{0,051} & \multicolumn{3}{|c|}{0,063} \\
\hline$p_{1-3}$ & \multicolumn{3}{|c|}{0,684} & \multicolumn{3}{|c|}{1,000} & \multicolumn{3}{|c|}{0,039} \\
\hline$p_{2-3}$ & \multicolumn{3}{|c|}{0,323} & \multicolumn{3}{|c|}{0,959} & \multicolumn{3}{|c|}{0,501} \\
\hline
\end{tabular}


ложно-положительный результат (т. е. выявлено заболевание), этот вариант диагностического поиска вряд ли можно считать адекватным.

3. "Средний" вариант: необходимым было наличие 4 показателей, соответствующих критериям обструкции: 1) АРД 1 или АРД 2 при спокойном или форсированном дыхании (достаточно было хотя

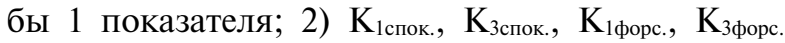
(достаточно хотя бы 1 показателя); 3) $\Delta \mathrm{K}_{1}$ или $\Delta \mathrm{K}_{3}$; 4) ИПК. Специфичность составила 96,9\% (из 129 ЗЛ у 125 получены истинно отрицательные результаты), чувствительность - 28,6\% (из 154 больных О3 у 44 получены истинно положительные результаты), диагностическая эффективность - 59,7 \%. Думается, полученные данные дают достаточные основания для использования этого варианта, например, при массовых обследованиях, особенно в амбулаторной практике.

Основные различия между больными Р3 и ЗЛ отражены в показателях АРД $2, \mathrm{~K}_{2}$ (т. е., в высокочастотном диапазоне), АРД,$\Delta \mathrm{K}_{3}$ и ИПК. Менее выраженные различия выявлены в группах больных О3 и Р3 (АРД 0, АРД $\left._{2}\right)$. Это может быть связано с общностью анатомо-функциональных изменений при тяжелых стадиях О3 и Р3, а также с малочисленностью группы больных Р3.

\section{Заключение}

Результаты данного исследования указывают на возможность применения БФГ для выявления обструктивных нарушений ФВД. Перспективными представляются и возможности использования БФГ в диагностике рестриктивных нарушений ФВД. Можно предположить, что характеристики дыхательных звуков, получаемых с помощью БФГ, могут служить дополнительными оценочными параметрами диагностики легочных заболеваний.

\section{Литература}

1. Гусейнов А.А., Айсанов З.Р., Чучалин А.Г. Акустический анализ дыхательных звуков: состояние вопроса. Пульмонология 2005; 6: 105-112.

2. Pasterkamp H., Kraman S.S., Wodicka G.R. Respiratory sounds. Advances beyond the stethoscope. Am. J. Respir. Crit. Care Med. 1997; 156 (3): 974-987.

3. Albella M., Formolo J., Penney D.G. Comparison of the acoustic properties of six popular stethoscopes. J. Acoustic. Soc. Am. 1992; 91: 2224-2228.
4. Pasterkamp H., Kraman S.S., Defrain P.D. et al. Measurement of respiratory acoustical signals: comparison of sensors. Chest 1993; 104: 1518-1525.

5. Wodicka G.R., Kraman S.S., Zenk G.M. et al. Measurement of respiratory acoustic signals. Effect of microphone air cavity depth. Chest 1994; 106: 1140-1144.

6. Sovijari A.R., Malmberg L.P., Paajanen E. et al. Averaged and time-gated spectral analysis of respiratory sounds. Repeatability of spectral parameters in healthy men and in patients with fibrosing alveolitis. Chest 1996; 109: 1283-1290.

7. American Thoracic Society Standartization of spirometry: 1987 update. Am. Rev. Respir. Dis. 1987; 136: 1285-1298.

8. Fiz A.J., Jane R., Salvatella D. et al. Analysis of tracheal sounds during forced exhalation in asthma patients and normal subjects: bronchodilator response effect. Chest 1999; 116: 633-638.

9. Пат. № 5062396 РФ. Способ регистрации дыхательных шумов / Малышев В.С., Ардашникова С.Н., Каганов С.Ю. и др. Бюл. изобрет.1995; 18.

10. Малышев В.С., Дементьева Г.М., Рюмина И.И. и др. Компьютерный диагностический комплекс Pattern. В кн.: Тезисы докладов Международной научно-технической конференции "Физика и радиоэлектроника в медицине и биотехнологии". Владимир; 1996. 36-37.

11. Kraman S.S., Wodicka G.R., Oh Y. et al. Measurement of respiratory acoustic signals. Effect of microphone air cavity width, shape, and venting. Chest 1995; 108: 1004-1008.

12. Провоторов В.М., Семенкова Г.Г. Исследование бронхиальной обструкции при бронхиальной астме с помощью туссофонобарографии. В кн.: 13-й Национальный конгресс по болезням органов дыхания. СПб.; 2003. 307.

13. Aeries J.E., Cheethman B.M. Current methods used for computerized respiratory sound analysis. Eur. Respir. Rev. 2000; 10 (77): 586-590.

14. Геппе Н.А., Малышев В.С., Лисицын М.Н. и др. Бронхофонография в комплексной диагностике бронхиальной астмы у детей. Пульмонология 2002; 2: 33-39.

15. Молдаванова Л.М., Кулаков Ю.В., Коренбаум В.И. и др. Билатеральная бронхофонография - акустический метод выявления патологического очага в легком. В кн.: 13-й Национальный конгресс по болезням органов дыхания. СПб.; 2003. 306.

\section{Информация об авторе}

Гусейнов Али Ажубович - к. м. н., ассистент кафедры факультетской терапии ГОУ ВПО "Дагестанская государственная медицинская академия"; тел.: (8722) 70-04-12; e-mail: ajub@inbox.ru

Поступила 23.01.09 (с) Гусейнов А.А., 2009

УДК 616.24-071.6 